\title{
ENCONTROS POSSÍVEIS: EXPERIÊNCIAS COM JOGOS TEATRAIS NO ENSINO DE CIÊNCIAS
}

\author{
Possible encounters: \\ experiences with theater games in science education
}

Thiago Ranniery Moreira de Oliveira ${ }^{1}$

Resumo: O que pode acontecer entre o Teatro e o Ensino de Ciências? Quais as potencialidades da composição Ensino de Ciências com jogos teatrais? Que agenciamentos podem surgir desse encontro? Ao seguir as trilhas da filosofia da diferença em educação, inspirada em Gilles Deleuze, investigase, a partir de uma cartografia, a experiência da oficina de teatro Ciência inCena. Nela, alunos-atores escolheram o conteúdo de peixes a ser trabalhado a partir de jogos teatrais. O processo de montagem de Pedro e o mar ou como os peixes hão de voar indica possibilidades de se pensar outras narrativas para os sujeitos e objetos das aulas de ciências e as relações que os comportam.

Palavras-chave: Ensino de ciências. Jogo teatral. Teatro.

\begin{abstract}
What can happen between Theater and Science Education? What are the potentialities for science teaching and theater games? Which outcomes may emerge from this meeting? By following in the tracks of the philosophy of difference in education, inspired by Gilles Deleuze, the experience of theater workshop Ciencia inCena is investigated. In it, student-actors chose the contents to work with in theater games about fish. The process of making the theater play Pedro e o mar ou como os peixes hão de voar indicates possibilities of thinking about other narratives in order to consider the subjects and objects of science classes and the relationships which constitute them.
\end{abstract}

Keywords: Science teaching. Theater games. Theater.

\footnotetext{
${ }^{1}$ Programa de Pós-graduação em Educação, Universidade Federal de Minas Gerais. Avenida Antônio Carlos, n. 6627, sala 1557. Pampulha, Belo Horizonte, MG, Brasil.31.270-901. tranniery@yahoo.com.br
} 


\section{Um pouco de possível, se não eu sufoco ... (DELEUZE, 1992, p. 131)}

A articulação entre Teatro e Ensino de Ciências, apesar de não muito produtiva, não se faz recente ${ }^{2}$. Entretanto, não se trata, propriamente, de ensinar ciências através de experiências com jogos teatrais. Submeter o Teatro ao Ensino de Ciências fadaria esse escrito a uma posição instrumentalista ${ }^{3}$, como se convencionou denominar no campo da Pedagogia do Teatro e do Teatro na Educação. De fato, a emergência por uma pedagogia do teatro ${ }^{4}$ e do teatro como pedagogia $a^{5}$, travada no âmbito das pesquisas em Teatro na Educação ${ }^{6}$, tem possibilitado ao teatro ser "cada vez mais senhor de suas próprias atitudes, solicitando para si o estatuto de arte autônoma capaz de disponibilizar a outros campos de saber suas idiossincrasias" (ICLE, 2008, p. 12). Por outro lado, reclamar, para este artigo, uma posição essencialista, como se falasse da possibilidade de explorar a produtividade dos jogos teatrais em ensino de ciências, valendo-se deles para fundamentar ou sustentar uma "nova" metodologia sobre ensinar ciências, parece soar demasiado antiteatral.

É preciso assumir que o que se faz aqui não é nenhuma coisa nem outra, embora se refira a ambos os campos. Em uma espécie de terceira margem do rio, retomando Guimarães Rosa, é, antes, um caminhar entre um e outro, andar pelo meio, estar sempre entre esses dois pontos, intermezzo (DELEUZE, 1998a). É um encontro, como aqueles nas noites brancas de Dostoievski (1988). "Encontrar é achar, é capturar, é roubar. [...] Um encontro é talvez a mesma coisa que um devir ou núpcias [...]. Encontram-se pessoas, mas também movimentos, idéias, acontecimentos, entidades" (DELEUZE, 1992, p. 15). É uma experimentação de Ensino de Ciências com Teatro. Ensino de Ciências $e$ Teatro. Ensino de Ciências + Teatro ${ }^{7}$. De um lado, um campo de ação cultural, marcado pela criação, pela transgressão, pelo movimento, pelo jogo (GUÉNOUN, 2004; COELHO, 2001). De outro, uma disciplina, um conjunto de práticas discursivas pedagógicas e científicas, livros didáticos, laboratórios, professoras e professores, alunos e alunas, lista de conteúdos, parâmetros curriculares. Interessam, assim, algumas perguntas para explorar o exercício do pensamento: o que pode acontecer entre um campo e outro? Que agenciamentos e acontecimentos podem surgir desse encontro fortuito e inevitável?

\footnotetext{
${ }^{2}$ Ver: Bailey; Watson (1998); Brouwer (1988; 1994); Braund (1999); Palmer (2000); Christofi; Davies (1991); McSharry; Jones (2000); Moreira; Rezende (2007).

${ }^{3}$ Ver a classificação entre abordagem de ensino de teatro instrumentalista versus essencialista, em Koudela (2006a), Japiassu (2001), Read (2001), Courtney (2003).

4 "Quando falamos em pedagogia teatral estamos nos referindo a uma reflexão sobre as finalidades, as condições, os métodos e os procedimentos relativos a processos de ensino/aprendizagem em teatro.” (PUPO, 2006, p. 109).

5 “a noção de teatro como pedagogia [...] pretende acentuar que o fazer teatral, em si, ensina sobre relacionamentos, expectativas, conflitos e emoções humanas, e é a atmosfera do trabalho e a vivência em grupo, que tornam significante a experiência" (CABRAL, 2008, p. 1).

${ }^{6}$ Ver algumas discussões em Koudela (2002, 2006b); Pupo (2006); Icle (2008); Cabral (2007; 2008).

${ }^{7}$ Notação inspirada na proposição de Tomaz Tadeu (2003).
} 
Encontros possíveis: experiências com jogos teatrais ...

Perguntas feitas porque a investigação da experiência da oficina de teatro Ciência in Cena foi efetuada à medida que explorava a "filosofia para profanos" ${ }^{8} \mathrm{e}$ aquilo que se convencionou chamar de pesquisas pós-críticas em educação (PARAÍSO, 2004; CORAZZA, 2001), deixando-se contagiar por suas potencialidades e alguns dos seus conceitos. Este escrito dispõe-se, simplesmente, a reacender a potência de evocação, de questionamento e de estranhamento embutida na relação Teatro com Ensino de Ciências. A meio caminho entre o Teatro e o Ensino de Ciências, a Educação em Ciências e a Arte, o gênero híbrido corre, por certo, o risco inevitável e óbvio de desgostar a todos, especialmente por parecer aleatório ou duvidoso. Teriam um quê de razão, se não fosse a circunstância particular de que determinadas experimentações teóricas têm, na divagação e na digressão, sua matéria-prima. Pois, na sua textura mais íntima, mesmo quando atreladas a aparatos acadêmicos rigorosos, as experimentações teóricas comportam um quinhão irredutível de ficção (PELBART, 1989). Ao invés de negar a dimensão ficcional do pensamento ${ }^{9}$, trato aqui de construir ressonâncias caleidoscópicas, de traçar linhas de fuga para desfazer certas ordens cristalizadas, lançar flechas, provocar abalos, abrir alas em um Ensino de Ciências que engendra multiplicidades e singularidades, a fim de criar outras fabulações de vida. Afinal, não é este um dos sonhos do pensamento: o de insuflar, na vida, uma grande e nova leveza lúdica?

\section{Todos a bordo: rotas de nau viajante}

Eis, aqui, o relato de uma insólita viagem ao mundo do Teatro no Ensino de Ciências, ao febril e vibrante mundo de um processo coletivo da montagem cênica de Pedro e o mar ou como os peixes hão de voar. Ciência inCena, uma oficina de teatro com 15 alunos de $8^{\circ}$ e $9^{\circ}$ ano, do Colégio de Aplicação, localizado no campus de São Cristóvão da Universidade Federal de Sergipe. Uma cartografia dos modos pelos quais o Teatro agencia outros modos de pensar o ensino de Ciências. Opção pela cartografia como método de investigação porque o fazer cartográfico é um modo de pesquisa implicado em embarcar na embriaguez do movimento pela própria mudança, na força e na potência da criação (DELEUZE; GUATTARI, 1997a). Nada mais adequado a uma experiência assim... Afinal, "numa cartografia, pode-se apenas marcar caminhos e movimentos, com coeficientes de sorte e de perigo. É o que chamamos de 'esquizoanálise', essa análise das linhas, dos espaços, dos devires” (DELEUZE, 2006, p. 48). Ao se recompor um mapa da oficina, aqui investigado, registra-se um conjunto de linhas dispersas, funcionando todas ao mesmo tempo, "em velocidades variadas" (DELEUZE, 1992, p. 47).

\footnotetext{
${ }^{8}$ Refiro-me a filósofos como: F. Nietzsche, B. Spinoza, M. Foucault e G. Deleuze. A filosofia produzida por esses filósofos tem sido chamada de "filosofia para profanos" porque, como sugere Larrauri (2005), trata-se de uma filosofia feita para não-filósofos. Entretanto, pondero que, como sugere Amorim (2000) e Wortmann e Veiga-Neto (2001), tal aporte teórico não parece ser usual na área de Educação em Ciências no Brasil.

${ }^{9}$ A ficção está sendo entendida, aqui, não em oposição ao real, pois tal oposição pode levar à suposição de que "fazer ficções" é uma operação risível. Inspirado em Nietzsche (2001), tomo que a ficção corresponde àquilo que existe mesmo, é nossa única atividade quando falamos em fabricar verdades.
} 
As linhas, elas mesmas, "são elementos constitutivos das coisas e dos acontecimentos” (DELEUZE; GUATTARI, 1996, p. 22), e, por isso mesmo, são constitutivas dos acontecimentos aqui investigados e dos modos de subjetivação que eles agenciam.

Como sugerem Deleuze e Guattari (1997a), para cartografar, é necessário analisar a longitude e a latitude. A longitude está relacionada às partes do corpo: do que esse corpo se compõe? Que linhas compunham a experiência da oficina? Já a latitude refere-se ao grau de potência de um corpo: quais são os afectos desse corpo? Que afectos eram movimentados na oficina? Cartografar uma oficina de teatro é, pois, construir um mapa aberto dos seus segmentos, poderes e territórios, e dos seus pontos de desterritorialização, por onde foge e faz fugir. Com duração total de cinco meses, as atividades da Ciência inCena aconteciam duas vezes semanais, somando um mínimo de seis horas de aula. Nelas, o grupo de alunos escolheu um conteúdo específico do Ensino de Ciências para ser o tema da oficina, a partir do qual trabalharíamos. Opção pelo conteúdo de peixes - e um espanto que, por um instante, tal escolha provocou. "Ah, o senhor quer moleza eh? Se vai fazer uma experiência que faça direito" - disse uma das alunas. Aceitamos, a partir daí, o risco para produzir "um campo de afectos não estruturados nem estruturáveis ou oficializados, consequentemente não fadados à repetição, ao tédio da experiência cooptada pela norma, pelo imaginário instituído" (LINS, 2005, p. 1239).

Os peixes, essas criaturas típicas de comunidades marinhas nectônicas ${ }^{10}$, exibem, geralmente, uma grande diversidade morfológica e de ciclos de vida (PAES, 2002). Contendo 27.977 espécies catalogadas, um pouco mais da metade de todos os vertebrados vivos descritos, os representantes do grupo ocupam uma diversidade de hábitats aquáticos (NELSON, 2006). Transcorreram pouco mais de trinta anos e os peixes são os sabores (LINS, 2005) dos saberes de diversos estudos conduzidos pelo Laboratório de Ictiologia do Departamento de Biologia (DBI/UFS), para caracterizar a ictiofauna dos estuários e da plataforma continental de Sergipe ${ }^{11}$. Este artigo, entretanto, não é dirigido só a pesquisadores de educação em ciências, professores de ciências, arte-educadores, mas aos que, alguma vez, já sentiram que essa vida morna, tola, enfadonha, que o Ensino de Ciências tem nos oferecido e alardeado como a única possível (FOUCAULT, 1986), esconde outras tantas, cuja beleza e tentação cabem reinventar.

Nos encontros da oficina, os jogos teatrais, uma das principais metodologias de trabalho e investigação em pedagogia do teatro (KOUDELA, 2002), foram trabalhados e adaptados em torno da investigação cênica proposta pelos alunos. Caso pudéssemos resumir, de algum modo, os mais variados estudos sobre metodologias de ensino de teatro, vislumbraríamos, mesmo que correndo o risco de sermos reducionistas, a emergência das influências do Jogo Dramático, tanto nas versões inglesa como francesa, do Teatro do Oprimido de Augusto Boal $(1980,1996,2005,2007)$ e do Sistema de Jogos Teatrais de Viola Spolin (1999, 2001, 2005), bem como as experimentações de Koudela (1991, 1992, 1996, 2001, 2006b) sobre o sistema de Jogos Teatrais de Spolin. Estou condenado, aqui, a me apropriar desses movimen-

\footnotetext{
${ }^{10}$ Conjunto dos seres animais que nadam livremente na coluna de água, deslocando-se por atividade própria, vencendo a correnteza das águas.

${ }^{11}$ Caracterizações da ictiofauna de diversos ambientes aquáticos de Sergipe podem ser encontradas em Alcântara (1989, 1992, 1996, 1997, 2000, 2006).
} 
Encontros possíveis: experiências com jogos teatrais ...

tos no território das metodologias de ensino de teatro, de forma que partículas desse universo se misturem às que já povoam o território do Ensino de Ciências e, na invisível química dessa mistura, se produza uma verdadeira transubstanciação. Uma antropofagia, relembrando Oswald de Andrade (1928), deglutindo e transmutando para engendrar uma operação que produz desvios ao invés de regras, para ativar outros movimentos nos fazeres em Ensino de Ciências. Afinal, o cartógrafo sabe que precisa inventar seu próprio caminho e refazê-lo a todo tempo (ROLNIK, 1989). Os conceitos das metodologias em ensino de teatro são operados sem preocupação de fidelidade com as correntes teatrais, são muito mais tratados com uma certa desenvoltura que o próprio teatro parece evocar.

\section{Todo corpo é uma enxurrada}

Cena 1. Um aluno-ator estende a mão à frente da face do outro. Ao som da Valsa de Amélie, começam a conduzir os corpos dos seus colegas pela sala. Em cima, em baixo, para a direita, para a esquerda, rolando no chão, subindo em cadeiras, roçando-se na parede, ora rápido como uma gazela, ora devagar como uma tartaruga. Se antes a mão, agora o braço é estendido para descrever os movimentos de nadadeiras de peixes. Em um balé contagiante, movimentos curtos e rápidos para pequenos peixes, como piabas e tainhas, movimento largos e amplos para grandes peixes pelágicos, ou movimento baixos e próximos ao chão para peixes associados ao fundo.

Cena 2. Um aluno-ator em frente ao outro. Entre, eles uma "película de água" garante que um é reflexo do outro. Uma dupla dança sibilarmente - está interpretando a água, outra simula inflar-se como um balão - está interpretando um baiacu; outra joga uma tarrafa e nela parece enroscar-se - é um pescador definitivamente desastrado.

Uma primeira rota dessa viagem: brincar com jogos e exercícios introdutórios da linguagem teatral. Aqui, os alunos eram convidados a jogar e a se envolverem nos jogos expondo-se claramente as regras de funcionamento. Primeiro, é preciso quebrar a resistência diante da vergonha (ou da confusão de teatro com exibicionismo). Expor o rosto em um jogo teatral é um perturbador momento de desestabilização. No regime de vida em que vivemos, no qual inauguramos a sensação do corpo próprio, essa individualidade necessita da produção de rostos. A aderência ao propagado modelo de subjetivação dominante só se dá por meio da máquina abstrata da rostidade (DELEUZE; GUATTARI, 1996). Modo próprio pelo qual um corpo é territorializado, individuado, é tornado campo de jurisprudência, erguendo os muros da subjetivação. Logo, o jogo teatral desterritorializa as linhas do rosto, para, em seguida, lançá-las em outro lugar, onde as linhas e os traços do rosto se tornam imprecisos; um lugar "fora-de-lugar", embaçado e nublado, onde as peças do jogo estão, de certo modo, embaralhadas. $\mathrm{E}$ os alunos sentem-se, ao menos de início, desestabilizados. "Ah, não era isso que en imaginava que fosse teatro". É somente, a partir daí, que podem entregar seus corpos ao jogo. 
Já há toda uma literatura em Ensino de Ciências para denunciar que o corpo permanece ausente de interesse epistemológico (OLIVEIRA; GOMES; CARDOSO, 2008), restrito a uma abordagem racional, mecanicista e fragmentária (MATOS, 2007); e até que a prática discursiva do corpo em fragmentação do ensino de ciências é parte das múltiplas estratégias de fabricação de sujeitos que circulam na escola e na sociedade (SOUZA, 2005). É bem verdade que, depois de Foucault (1999), não podemos mais deixar de olhar que os currículos escolares estão envolvidos em processos de produção de corpos dóceis, manipuláveis e localizáveis. Mas corpos podem ser mais que isso. Como coloca Deleuze (2002), ninguém sabe, ainda, do que pode um corpo, daquilo que um corpo é capaz.

No Teatro, corpos se atraem, se repulsam, se alteram, fazem alianças, se penetram, se excluem. Corpos são fluxos de energia (DELEUZE; GUATTARI, 1996), enxurradas correndo sempre pelo meio. Corpos são superfícies de inscrição em dinâmica de aprendizagem. Um aprendizado que nunca se encerrará na aquisição de um saber, um aprendizado que não é reproduzir, mas inaugurar, inventar o ainda não existente (SCHÉRER, 2005). Aprender que não se contenta em repetir um saber já instituído, que não se encerra na recognição, no reconhecimento, na representação, mas, ao contrário, é um incessante movimento que desloca, que promove desterritorializações naquilo que já está constituído e organizado. Aprender é abrir-se e refazer os corpos, agenciar atos criadores, refazer a vida, encontrar a diferença de cada um e seguir um caminho que ainda não foi percorrido; é abrir-se a uma coisa qualquer que desperte o desejo, que faz girar o movimento (PARAÍSO, 2010). De tal forma que corpos aprendem... Corpos que, quando jogam, não só aprendem determinado saber científico, mas aprendem que a partir disso é possível instaurar um mundo novo, é possível fazer algo com ele, a partir dele.

Os corpos não estavam na oficina para "representar" conteúdos científicos em forma de teatro, para representar acontecimentos. Antes, os acontecimentos estão nos/são os próprios corpos em experiências de jogo. $\mathrm{O}$ acontecimento

[...] esquiva todo presente porque está livre das limitações de um estado de coisas, sendo impessoal e pré-individual, neutro, nem geral nem particular [...] ou antes [...] não tem outro presente senão o do instante móvel que o representa, $[. .$.$] lançando por toda a parte suas singularida-$ des. (DELEUZE, 2000, p. 178)

O acontecimento exprime as transmutações que fazem do corpo uma matéria fluida, que fazem da vida uma potência a ser vivida. De modo que "não se perguntará qual o sentido de um acontecimento: o acontecimento é o próprio sentido" (DELEUZE, 2000, p. 34). Os corpos em cena não relatam acontecimentos a serem "entendidos" ou "decifrados", mas são o próprio acontecimento, o lugar onde este é chamado a se produzir. É por meio do jogo que a matéria é dada para ser transgredida, subvertida, transvalorada, pois é, ali, naquele espaço, que o aluno-ator experiencia diferentes e múltiplas possibilidades de existir. Há de se valorizar no jogo, justamente, os aspectos marginais dos jogos, como o azar, o inesperado, o improviso, o descontínuo, porque o jogo teatral convoca o que aprendemos a chamar de "saber científico" e a sua experiência de aprendizagem para responder às necessidades do corpo, encarnando-se na vida, deixando-se aberto ao acaso, abrindo-se à liberdade e à dinâmica das forças para não deixar as coisas se assentarem, tirar-lhes do estupor. 
Encontros possíveis: experiências com jogos teatrais ...

\section{Uma poesia para sair das lógicas já dadas}

Cena 3. Jogo "Começo e Fim": um aluno-ator rola no chão para sentir-se vivendo na lama; outro empilha caixas invisíveis para sentir-se na região de substrato rochoso da plataforma continental de sergipana; outro passa o queixo no chão para alimentar-se como uma carapeba; outra aluna amarra um casaco no rosto de forma a deixar os braços soltos e passá-los no chão do mesmo modo que faz um bagre ao se alimentar; outra aluna manipula um aparelho de mergulho e encara a plateia como se estivesse em um aquário.

Cena 4. Uma aluna dança como uma hippie: é uma arraia nadando no fundo do estuário. Um aluno interpreta um "emo": é um baiacu de comportamento solitário.

Postas, assim, as cenas trazem à tona como os alunos experienciam os "ambientes naturais" que estavam em questão: mar e estuário. Spolin (2005) evoca o experienciar em um jogo teatral para descrever o modo pelo qual o ator penetra no ambiente, envolve-se com ele, o que exige dele envolvimento intuitivo. Intuição que, para Spolin (2005), é o nível mais vital para a situação de aprendizagem. Intuição que, se seguirmos Bergson (1984), é obstinada pelo movimento, é aquilo que toca, que provoca o espírito e o põe em estado de mudança. O jogo teatral é, assim, um lugar de provocar mudanças, transformações, experiências. Experiência como tudo aquilo que nos toca, que nos passa, que nos acontece, que nos provoca, que nos tira do lugar (LARROSA BONDÍA, 2002). De modo que, talvez, nunca saibamos como um jogo teatral toca alguém. Mas me interessa, aqui, dispor que jogo teatral torna-se capaz de mobilizar uma outra experiência em Ensino de Ciências. Na experiência, saímos sempre transformados e o mundo também se transforma (PARAÍSO, 2011). Esses jogos acabam funcionando como linhas de fuga (DELEUZE; GUATTARI, 1997b) desejadas, criadoras de situações inteiramente imprevistas, que nem sempre vêm por vontade própria das pessoas, mas perpassam um conjunto de corpos e afectos.

A experiência/experimentação provocada no/e pelo jogo teatral é uma permissão à passagem de afectos (DELEUZE; GUATTARI, 1997c) nos corpos. Abertura do corpo do ensino de Ciências às afecções, àquilo que toca, aos devires que atravessam os homens. É isso que amplia a habilidade de o aluno-ator envolver-se com o mundo e com a criação, pois, aqui, deixa-se de ser o que se é e experimenta-se/experiencia-se tornar-se outra coisa completamente diferente, absurdamente improvável. Arraia-hippie, baiacu-emo, corpo-rola-chão. Ou seja, o modo pelo qual o aluno-ator fisicaliza (SPOLIN, 2005), apresenta, em nível físico e não verbal, a realidade que se instaura, em que seu corpo é uma narrativa. É fundamental que o alunoator aprenda a comunicar fisicamente a realidade que se cria, apesar das insistências e recorrências dos alunos em tentarem explicar, explanar, esclarecer aquilo que realmente tinham a intenção de fazer. Somente assim, a invenção de si e do mundo agenciada em jogo teatral poderá ser ampliada. "Nada aprenderemos com aquele que nos diz: faça como eu. Nossos únicos mestres são aqueles que nos dizem faça comigo e que, em vez de nos proporem gestos a serem reproduzidos, sabem emitir signos a serem desenvolvidos no heterogêneo" (DELEU- 
ZE, 2006, p. 57). Os jogos teatrais, aqui, não são evasão de um real que foi descrito pela Ciência e cabe ao Ensino de Ciências apresentar. Os jogos são, antes, evocação de uma nova realidade, de uma outra narrativa, de uma outra história.

\section{A nau e a conquista do território cênico}

Eis que é chegado o momento crucial de se conectarem as experiências/experimentações dos jogos teatrais em um texto dramático. Mas o que move um texto dramático? Se os jogos valem por si mesmos, inserir um texto já não seria condenar o jogo à codificação e à interpretação? O que torna o texto dramático diferenciável de outros textos? $\mathrm{Na}$ tendência atual, em que todo texto é teatralizável, em que marcas, como diálogos, conflitos e situações dramáticas, já não são condições essenciais, a cena teatral tornou-se não mais o lugar de enunciação do texto, mas de sua alteridade absoluta (PAVIS, 2003). O roteiro Pedro e o mar on como os peixes hão de voar não é, portanto, um objeto homogêneo, nem representa, efetivamente, as cenas construídas nos/e pelos jogos. É, antes, no sentido de Barthes (2004), um tecido, da ideia gerativa de que o texto se trava em um entrelaçamento perpétuo, no qual o sujeito se desfaz tal qual uma aranha que se dissolve nas secreções constitutivas de sua teia.

Ou seja, o roteiro é apenas um meio, um estopim da criação. Não pode, nem deve ser compilação dos jogos realizados até o momento de sua escrita, pois poderia prender as experiências dos jogos em significados e significações de um texto. Nem pode ser ponto de partida para a construção de um futuro espetáculo, pois submeteria a oficina à necessidade de um resultado final, desqualificando a força produtiva do processo com jogos teatrais. Parece ser necessário pensar o próprio processo de produção do roteiro em si mesmo. Ao se usar, por exemplo, a técnica do teatro-jornal para a criação de cenas a partir de um texto não dramático, como o Manual Didático de Peixes Marinhos e Estuarinos do Estado de Sergipe (OLIVEIRA, 2009). Exercício do qual saíram os personagens e conflitos criados pelos alunos para o roteiro do espetáculo. Pedro e o mar ou como os peixes hão de voar descreve as aventuras de Pedro, que após cair do barco em uma noite de tempestade, parte em busca de seu irmão desaparecido no fundo de um estuário. Nesse caminho, se juntam a ele três peixes de espírito livre e aventureiro, conhecedores dos fundos lamosos estuarinos: a Raia Hippie, Bagre e Tapa. Na saga, Pedro conhece Cardumes de Córros, a Corrente de Água, o Baiacu Emo, o Velho Ninquim, para descobrir que seu irmão estava sob o controle da Moreia Perigosa. Não há como descrever em detalhes a encenação que mesclava linguagem do cinema, da dança, artes maciais e muita música contemporânea, indo do hip hop ao tango, em cenas divertida e milimetricamente coreografadas.

O Teatro somado ao Ensino de Ciências investe na produção de um conhecimento encarnado, um pensamento que se produz no/pelo corpo, um saber alegre e capaz de dançar, um saber profano (LARROSA, 2006). Sim! O jogo teatral não só investe na abertura do corpo, mas, também, na reinvenção de uma economia de afectos. Invoca a função política da leveza e da alegria na experiência do aprender, pois aprende de Spinoza (2007) que alegria é vida que resiste à morte. É vida que se instaura em um processo que nos desafia a olhar a multiplicidade, em pensar um mundo que difere permanentemente de si mesmo. O próprio Deleuze um dia afirmou: "não basta dizer Viva o múltiplo, grito de resto difícil de emitir. É preciso fazer o 
Encontros possíveis: experiências com jogos teatrais ...

múltiplo" (DELEUZE; GUATTARI, 1996, p. 13). É jogando teatro com o Ensino de Ciências e suas metodologias de ensino/aprendizagem que se faz o múltiplo como possibilidade de aprendizagem, que a própria aprendizagem passa a "constituir o espaço em que os pontos relevantes se retornam uns aos outros em que a repetição se forma ao mesmo tempo que se disfarça" (DELEUZE, 2006, p. 54). O Teatro no Ensino de Ciências faz nascer, no Ensino de Ciências, a sensibilidade de aprender aquilo que só pode ser sentido.

A Oficina de Teatro com o Ensino de Ciências configura-se como um momento de agenciamento de experiências. E agenciamento não passa disso, de um "arranjo, a combinação de elementos heterogêneos, díspares, fazendo surgir algo de novo, que não se pode reduzir a nenhum dos elementos isolados que o compõem" (TADEU, 2004, p. 157). Essa composição dos agenciamentos coloca em jogo que tudo, na combinação desta viagem de Ensino de Ciências + Teatro, são velocidades e afectos, "no sentido de que tudo aí é relação de movimento e repouso entre moléculas ou partículas, poder de afetar e ser afetado" (DELEUZE; GUATTARI, 1997a, p. 43). Os agenciamentos dissolvem, assim, as essências das coisas, sejam elas quais forem, e se, assim, são alimentados, os agenciamentos são capazes de produzir "verdadeiras fulgurações, surpreendentes instantâneos na monotonia cinza da matéria já formada" (TADEU, 2004, p. 163). Nos agenciamentos múltiplos de encontros, vivencia-se um devir possível de repensar as experiências em Ensino de Ciências, de inventar outras fábulas para seu acontecimento.

\section{Subindo as cortinas do espetáculo}

Ao contestar a validade e a soberania dos princípios da razão e da palavra, a forma pelo qual o Ensino de Ciências não tem passado de mais uma metanarrativa educacional que tem fixado o fluxo incontrolado das coisas, o Teatro propõe que o aluno-ator seja deslocado do lugar fixado da sala de aula - aquele sujeito moderno, racional e autônomo inventado pelo Iluminismo e que caberia ao Ensino de Ciências produzir dentro da escola - para colocá-lo dentro de um espaço cênico no qual o presente é uma invenção. Uma paródia das verdades estabelecidas, um afastamento crítico em relação às verdades antes tomadas como inquestionáveis (FOUCAULT, 2007). É na atitude de invenção, de criação - o que implica, em certo ponto, transgressão e destruição - que o teatro se aproxima do Ensino de Ciências. Ensino de Ciências que, agora, tem aulas com o Teatro de como tencionar seus limites, fabular, inventar ficções, fazer poesia, fazer rir.

Aqui, o teatro abre, ao menos, três potencialidades/possibilidades. O sujeito epistemológico clássico da educação científica, que poderia afirmar uma identidade coerente em si mesmo, agora vacila, se desfaz, não passa de uma invenção. E, se é uma invenção, é sempre possível inventar outros modos de ser e existir na educação em ciências, modos de tornar-se, de entrar em devir. Ao pôr em suspeita os valores supostamente universais da cultura política do Iluminismo (PETERS, 2000), o Teatro abre essa possibilidade de transmigração da existência, de não precisarmos passar a vida inteira usando o mesmo esqueleto. Os objetos de estudo não são, também, mais os depositários da estabilidade e da representação, mas, antes, se decompõem em fragmentos e ruínas. Enfim, o próprio processo de significação surge da corrosão dos laços vivos e materiais entre as coisas, colocando os seres envolvidos em um perpétuo 
movimento de translocação, transformação. Movimento que vem conclamar, também, uma recusa ao Uno, e tudo que vem nele entranhado: à identidade, à representação, à totalidade, ao sujeito, à completude, à plenitude, à origem, à essência, ao progresso, à evolução, em favor da variação, da dissonância, da singularidade, da multiplicidade.

Por conseguinte, o conceito de aula de Ciências também se transforma. Não é mais um resultado de uma elaboração a priori, é concebida em processo, em um working progress (COHEN, 2004). Expostos ao caos, alunos e professor se deixam trabalhar por justaposições disjuntivas, por livre associação, se deixam trabalhar como quem brota ervas daninhas. Tal sistema de multiplicidades só "poderia ser chamado rizoma" (DELEUZE; GUATTARI, 1996, p. 13). O Teatro + Ensino de Ciências instaura uma outra imagem do aprender e da sua relação com o ensinar, experiência sem a qual não há transformação na sala de sula, pois, como bem lembra Foucault (2006), uma das práticas fundamentais da liberdade consiste em pensar de outro modo. Essa imagem, agora, é a da aula-rizoma, na qual se

conecta um ponto qualquer com outro ponto qualquer, e cada um de seus traços não remete necessariamente a traços de mesma natureza, [...] Ele não é feito de unidades, mas de dimensões, ou antes, de direções movediças. Não tem começo nem fim, mas sempre um meio, pelo qual ele cresce e transborda. (DELEUZE; GUATTARI, 1996, p. 31)

Uma aula, assim, "arranca do culto das origens, para afirmar a potência de um meio, [...] arranca das estruturas, para traçar as linhas de fuga" (DELEUZE; GUATTARI, 1997b, p. 40). Uma aula, assim, é alegre, joga com as certezas, prefere as disjunções, um aula, assim, é ato de criação.

Fazer uma composição do teatro com o ensino de ciências é, pois, em última instância, abrir caminhos para a passagem de linhas "de fuga ou de ruptura, abstrata, mortal e viva, não segmentar" (DELEUZE, 1997b, p. 67), que "são linhas de desterritorialização pelas quais um território foge sem parar" (TADEU, 2004, p. 188). Elas que parecem tão incertas, tão sufocadas, ausentes às vezes, ou esgotadas, diante da dominância da regularidade, do estriamento e do controle, da paisagem fria e cinzenta de todos os dias. A linha de fuga está, assim, posta sob o signo do indiscernível e da disjunção inclusa. Afinal de contas, fugir não é

renunciar às ações, nada mais ativo que uma fuga. É o contrário do imaginário. É igualmente fazer fugir, não obrigatoriamente os outros, mas fazer fugir algo, fazer fugir um sistema como se arrebenta um tubo... Fugir é traçar uma linha, linhas, toda uma cartografia. (DELEUZE, 1998b, p. 47)

Uma cartografia de um mundo explodido em cacos, de um Ensino de Ciências que aprende a como inventar ficções, ser poético, a não deixar paralisar o pensamento, a permitir proliferar a diferença. 
Encontros possíveis: experiências com jogos teatrais ...

Referências

ALCÂNTARA, A. V. A ictiofauna do estuário do rio Sergipe. In: ALVES, J. P. H. (Org). Rio Sergipe: importância, vulnerabilidade e preservação. Aracaju: Ós Editora, 2006. p. 111-142.

Caracterização da ictiofauna do estuário do rio Vaza-Barris em período chuvoso e de estiagem. Aracaju, 1991-1992. 2 v. (Relatório técnico apresentado à ADEMA).

Ecologia da ictiofauna do estuário do rio Sergipe (estado de Sergipe, Brasil). 1989. 2 v. Tese (Doutorado) - Instituto de Biociências, Universidade de São Paulo, São Paulo, 1989.

Ictiofauna. In: ALVES, J. P. H. (Ed.). Avaliação da qualidade da água do rio Sergipe na região de influência dos descartes do campo de Riachuelo. Aracaju, 1996. p. 172-223. (Relatório técnico final convênio Petrobras/FAPESE, 09/95).

Ictiofauna. In: ALVES, J. P. H. (ed.). Condições ambientais do rio Japaratuba na região de influência dos descartes do campo de Carmópolis. Aracaju, 1997. p. 115198. (Relatório técnico final dos períodos 1990/91 e 1996/97, apresentado à Petrobras, em atendimento ao convênio FAPESE/UFS, 10/97).

Ictiofauna. In: GUIMARÃES, C. R. P. (Coord.). Monitoramento da área de influência das plataformas petrolíferas da costa do estado de Sergipe. Aracaju, 2000. p. 130-155. (Relatório técnico final apresentado à Petrobras em atendimento ao convênio FAPESE/UFS, 25/99).

AMORIM, A. C. R. Os olhares do caminhante nos territórios do ensino de biologia. 2000. 205 f. Tese (Doutorado em Educação) - Faculdade de Educação, Universidade Estadual de Campinas, Campinas, 2000.

ANDRADE, O. Manifesto antropófago. Revista de Antropofagia, São Paulo, ano 1, n. 1, maio 1928.

BAILEY, S; WATSON, R. Establishing basic ecological understanding in younger pupils: a pilot evaluation of a strategy based on drama/role play. International Journal of Science Education, London, v. 20, n. 2, p. 139-152, 1998.

BARTHES, R. O prazer do texto. 4. ed. São Paulo: Perspectiva, 2004.

BERGSON, H. O pensamento e o movente. São Paulo: Abril Cultural, 1984. (Coleção Os pensadores).

BOAL, A. Jogos para atores e não-atores. 7. ed. Rio de Janeiro: Civilização Brasileira, 2007.

O arco-íris do desejo: método Boal de teatro e terapia. Rio de Janeiro: Civilização Brasileira, 1996.

Stop: c'est magique!. Rio de Janeiro: Civilização Brasileira, 1980. 
Oliveira, T. R. M.

BOAL, A. Teatro do oprimido e outras poéticas políticas. Rio de Janeiro: Civilização Brasileira, 2005.

BRAUND, M. Electric drama to improve understanding in science. School Science Review, London, v. 81, n. 294, p. 35-41, Sep. 1999.

BROUWER, W. The image of the physicist in modern drama (Part 2). American Journal of Physics, New York, v. 62, n. 3, p. 234-240, 1994.

The image of the physicist in modern drama. American Journal of Physics, New York, v. 56, n. 7, p. 611-617, 1988.

CABRAL, B. A. V. O texto e o teatro na escola - desafiando o habitus; cruzando fronteiras. In: CONGRESSO BRASILEIRO DE PESQUISA E PÓS-GRADUAÇÃO EM ARTES CÊNICAS, 5., 2008, Belo Horizonte. Anais... Belo Horizonte: ABRACE, 2008. p. 1-5. . Pedagogia do teatro e teatro como pedagogia. In: REUNIÃO CIENTÍFICA DE PESQUISA E PÓS-GRADUAÇÃO EM ARTES CÊNICAS, 4., 2007, Belo Horizonte. Comunicações... Belo Horizonte, ABRACE, 2007. p. 1-4.

CHRISTOFI, C.; DAVIES, M. Science through drama. Education in Science, Hartfield, n. 141, p. 28-29, Jan. 1991.

COELHO, T. O que é ação cultural? São Paulo: Brasiliense, 2001.

COHEN, R. Working in progress na cena contemporânea. São Paulo: Perspectiva, 2004.

CORAZZA, S. O que quer um currículo?: pesquisas pós-críticas em educação. Petrópolis: Vozes, 2001.

COURTNEY, R. Jogo, teatro e pensamento: as bases intelectuais do teatro na educação.

2. ed. São Paulo: Perspectiva, 2003.

DELEUZE, G. Conversações. São Paulo: 34, 1992.

. Diferença e repetição. Rio de Janeiro: Graal, 2006.

Espinosa: filosofia da prática. São Paulo: Escuta, 2002.

Lógica do sentido. Rio de Janeiro: Jorge Zahar, 2000.

Proust e os signos. Rio de Janeiro: Forense Universitária, 1998a.

. Uma conversa, o que é e para que serve. In: DELEUZE, G; PARNET, C.

Dialógos. São Paulo: Escuta, 1998b. p. 9-47.

DELEUZE, G.; GUATTARI, F. Mil platôs: capitalismo e esquizofrenia. São Paulo: 34, 1996, v. 1.

Mil platôs: capitalismo e esquizofrenia. São Paulo: 34, 1997a. v. 4.

Mil platôs: capitalismo e esquizofrenia. São Paulo: 34, 1997b. v. 3.

O que é a filosofia? São Paulo: 34, 1997 c. 
Encontros possíveis: experiências com jogos teatrais ...

DOSTOIEVSKI, F. Noites brancas. Santiago: Editorial Santiago, 1988.

FOUCAULT, M. Arqueologia do saber. Rio de Janeiro: Forense, 1986.

Vigiar e punir: nascimento da prisão. São Paulo: Vozes, 1999.

Estratégia poder-saber. Rio de Janeiro: Forense Universitária, 2006. (Coleção

Ditos e escritos, v. 4).

História da sexualidade I: a vontade de saber. Rio de Janeiro: Graal, 2007.

GUÉNOUN, D. O teatro é necessário? São Paulo: Perspectiva. 2004.

ICLE, G. Pode o teatro dizer a verdade? In: REUNIÃO ANUAL DA ASSOCIAÇÃO

NACIONAL DE PÓS-GRADUAÇÃO E PESQUISA EM EDUCAÇÃO, 31, 2008,

Caxambu. Anais... Disponível em: <http://www.anped.org.br/reunioes/31ra/

trabalhos_ge.htm>. Acesso em: 19 mar. 2009.

JAPIASSU, R. O. Metodologia do ensino do teatro. Campinas: Papirus, 2001.

KOUDELA, I. D. A nova proposta do ensino do teatro. Sala Preta (USP), São Paulo, v. 1, p. 233-239, 2002.

Brecht na pós-modernidade. São Paulo: Perspectiva, 2001.

Brecht: um jogo de aprendizagem. São Paulo: Perspectiva; Edusp, 1991.

Jogos teatrais. São Paulo: Perspectiva, 2006a.

Pedagogia do teatro. In: CONGRESSO BRASILEIRO DE PESQUISA E

PÓS-GRADUAÇÃO EM ARTES CÊNICAS, 4., 2006, Rio de Janeiro. Anais... Rio de Janeiro: ABRACE, 2006b. p. 124-125.

Texto e jogo. São Paulo: Perspectiva; Fapesp, 1996.

Um vôo brechtiano. São Paulo: Perspectiva, 1992.

LARRAURI, M. La potencia según Nietzsche. Valência: Tàndem, 2005.

LARROSA, J. Pedagogia profana: danças, piruetas e mascaradas. 4. ed. Belo Horizonte: Autêntica, 2006.

LARROSA BONDÍA, J. Notas sobre a experiência e o saber da experiência. Revista Brasileira de Educação, Rio de Janeiro, n. 19, p. 20-28, 2002.

LINS, D. Mangue's school ou por uma pedagogia rizomática. Educação \& Sociedade, Campinas, v. 26, n. 93, p. 1229-1256, Set./Dez. 2005.

MATOS, S. O. A construção de representações sobre corpo na sociedade e o papel da escola na desconstrução dos padrões impostos. 2007. 146 f. Dissertação (Mestrado em Educação) - Centro de Educação, Universidade Federal de Santa Maria, Santa Maria, 2007.

McSHARRY, G.; JONES, S. Role-play in science teaching and learning. School Science Review, London, v. 82, n. 298, p. 73-82, 2000. 
Oliveira, T. R. M.

MOREIRA, L. M.; REZENDE, D. B. O jogo teatral nos processos de ensino e aprendizagem em ciências: um estudo de caso. In: ENCONTRO NACIONAL DE PESQUISA EM ENSINO DE CIÊNCIAS, 6., 2007, Florianópolis. Resumos... Florianópolis: Abrapec, 2007. p. 332.

NELSON. J. S. Fishes of the world. 4. ed. Hoboken: John Wiley, 2006.

NIETZSCHE, F. A gaia da ciência. São Paulo: Companhia das Letras, 2001.

OLIVEIRA, T. R. M. Teatro no ensino de ciências: por formas alternativas de produção e representação do conhecimento. 2009. 198f. Trabalho de conclusão de curso (Graduação em biologia) - Departamento de Biologia, Universidade Federal de Sergipe, São Cristóvão, 2009.

OLIVEIRA, T. R. M.; GOMES, C.; CARDOSO, L. R. Poéticas da fragmentação: pensar o corpo no ensino de ciências. In: COLÓQUIO INTERNACIONAL DE CIÊNCIA, TECNOlOGiA E DESENVOlVIMENTO, 4., 2008, Aracaju. Atas... Aracaju, 2008. p. $115-130$.

PAES, E. T. Nécton marinho. In: PEREIRA, R. C.; SOARES-GOMES, A. (Org). Biologia marinha. Rio de Janeiro: Interciência, 2002. p. 158-193.

PALMER, D. H. Using dramatizations to present science concepts. Journal of College Science Teaching, Arlington, v. 29, n. 3, p. 187-190, dez. 1999/jan. 2000.

PARAÍSO, M. P. Pesquisas pós-críticas em educação no Brasil: esboço de um mapa. Cadernos de Pesquisa, São Paulo, v. 34, n. 122, p. 283-303, 2004.

. É possível um currículo fazer desejar? In: PARAísO, M. P. (Org). Pesquisas sobre currículos e culturas. Curitiba: CRV, 2010. p. 153-168.

Raciocínios generificados no currículo escolar e possibilidades de aprender. In: LEITE, C. et al. (Org.). Políticas, fundamentos e práticas do currículo. Porto: Porto Editora, 2011. p. 147-160.

PAVIS, P. Dicionário do teatro. São Paulo: Pespectiva, 2003.

PELBART, P. P. Da clausura de fora ao fora da clausura. São Paulo: Brasiliense, 1989.

PETERS, M. Pós-estruturalismo e filosofia da diferença. Belo Horizonte: Autêntica, 2000 .

PUPO, M. L. Sinais de teatro-escola. Humanidades, Brasília, n. 52, p. 109-115, nov. 2006. (Edição especial).

READ, H. A educação pela arte. São Paulo: Martins Fontes, 2001.

ROLNIK, S. Cartografia sentimental: transformações contemporâneas do desejo. São Paulo: Estação Liberdade, 1989.

SCHÉRER, R. Aprender com Deleuze. Educação \& Sociedade, Campinas, v. 26, n. 93 , p. 1183-1194, set/dez 2005. 
Encontros possíveis: experiências com jogos teatrais ...

SOUZA, N. G. S. O corpo: inscrições do campo biológico e do cotidiano. Educação \& Realidade, Porto Alegre, v. 30, n. 1, p. 169-186, jan/jun 2005.

SPINOZA, B. Ética. Belo Horizonte: Autêntica, 2007.

SPOLIN, V. Improvisação para o teatro. São Paulo: Perspectiva, 2005.

Jogos teatrais. São Paulo: Perspectiva, 2001.

O jogo teatral no livro do diretor. São Paulo: Perspectiva, 1999.

TADEU, T. A arte do encontro: Spinoza + Currículo + Deleuze. In: CORAZZA, S.;

TADEU, T. Composições. Belo Horizonte: Autêntica, 2003. p. 59-74.

. Um plano de imanência para o currículo. In: CORAZZA, S; TADEU, T.;

ZORDAN, P. Linhas de escrita. Belo Horizonte: Autêntica, 2004. p. 127-205.

WORTMANN, M. L. C.; VEIGA-NETO, A. Estudos culturais da ciência e da educação. Belo Horizonte: Autêntica, 2001.

Artigo recebido em 15/08/2011. Aceito em 11/02/2012. 